\title{
Proclamations and Paraphernalia: \#Bellwether, Editor's Notes, and the Art of Remixing the Political Document
}

\author{
ROOPA VASUDEVAN
}

New Media Artist \& Doctoral Student, University of Pennsylvania

\begin{abstract}
In 2016 I created an installation entitled \#Bellwether, which was a visual exploration of social media content surrounding the 2016 United States presidential primaries, focused specifically on voters in Ohio. Over the course of a year, I collected more than 14 million public Twitter posts that referenced the candidates by name, and repurposed the design of their campaign merchandise to reflect voter sentiment, replacing the curated messaging that they were pushing into the political sphere. After the election, I collected public data from Trump's administration-including tweets from the@realDonaldTrump account, executive orders and memoranda and transcripts of interviews and news conferences - and edited the text of the US Constitution from his perspective, using the data to justify changes I made to the original text. I presented the final work in the form of a Presidential Executive Order, mirroring everything from typography to paper choices to the leather holders in which Executive Orders are publicly presented after signing. This creative study explores the lessons learned from these two projects; specifically, I examine the appropriation of political design and its signifiers. I argue that by manipulating and subverting this visual language, the work attempts to counter monolithic narratives perpetuated by dominant political systems, while illuminating the effects of media, technology and the Internet on our perceptions of the government and those who serve in it. By employing alternate historical narratives, the speculative nature of these works also offers a way of imagining a more nuanced approach to current political analysis and meaning-making.
\end{abstract}

\section{INTRODUCTION}

Campaign buttons, presidential proclamations, government seals: American politics has its own unique visual language that serves to cement certain modes of discourse and procedure as standard within the public imagination. Residents and citizens of the United States use these design conventions as a type of visual shorthand, allowing us to make inferences about the meaning and intention of particular documents and about those who use or adopt them. A lawn sign containing a political candidate's name unequivocally sends out a message of support, while the signing and presentation of a proclamation lends an official, irrefutable air to the contents of a document. 
Rarely do we question the functions or goals of these objects. More often, our concerns rest with the people and ideologies that these things signify, rather than the work that is done through the documents themselves to perpetuate standards, traditions and political rituals.

Two of my recent art projects seek to disturb some of these well-worn connections, using the visual signifiers of American politics to unearth fundamental questions about what they are, who they represent, and what we expect of them. In 2016 I created an installation entitled \#Bellwether, which was a visual exploration of social media content surrounding the 2016 United States presidential primaries, focused specifically on voters in Ohio. ${ }^{1}$ During the course of a year, I collected over 14 million public Twitter posts that referenced the candidates by name and repurposed the design of their campaign merchandise to reflect voter sentiment, replacing the curated messaging that they were pushing into the political sphere. After Donald Trump won the election and was inaugurated as the $45^{\text {th }}$ President of the United States, I turned my attention to his online data trail. In my durational project Editor's Notes, I edited the text of the Constitution to reflect political views and stances espoused by the Trump administration, in order to juxtapose the ephemeral and often informal nature of his presidential output with the formality and tradition of official government documentation.

Both projects attempt to take these contextually specific texts and visuals, which we take for granted as a standard part of the American political process, and alter their content and meaning in order to call into question the very nature of those traditions - who they serve, what they mean and what they accomplish. In this creative study of both of these pieces, I argue that by manipulating and subverting this visual language, these artworks attempt to counter monolithic narratives perpetuated by dominant political systems, while illuminating the effects of media, technology and the Internet on our perceptions of the government and those who serve in it. In addition, by employing alternate historical narratives, the speculative nature of these works also offers a way of imagining a more nuanced approach to current political analysis and meaningmaking. These artworks can thus serve as a form of political challenge and commentary, even as they borrow from highly traditional visual customs, through their multifaceted incorporation of data from a variety of sources and their juxtaposition of diametrically opposed points of view. ${ }^{2}$

\section{\#BELLWETHER}

\#Bellwether, which I started in 2015 during the initial stages of the 2016 presidential primary campaign, began as an attempt to make sense of social media's place in the mercurial world of political public opinion - while advocating for the conception of the Ohio voter as an individual rather than as part of a uniform bloc to be won over every four years. ${ }^{3}$ The project was also a response to efforts made by tech companies and social media platforms to position the data coming from those services as a more "accurate" or "representational" basis for gauging voter sentiment. ${ }^{4}$ While social media initially promised to be an interesting form of evaluating public opinion, it became clear through my research that this data was often shoehorned into standard approval/disapproval binaries and depicted in the manner of traditional political horse race polling. ${ }^{5}$ Thus, the project evolved into a celebration of the voice of the Ohio voter, and the diversity and fickle nature of opinions held by the state's population.

I used Twitter's application programming interface (API) to collect any post I could find in which a candidate from either party was mentioned by name. ${ }^{6}$ I wrote a script in the Python programming 
language, utilizing the open source "Python Twitter Tools"7 library, which queried the API for the names every five seconds; it then saved both the texts of the resulting posts and, where possible, either the posts' geolocations or the locations included in the users' profiles to a text document. This script ran without stopping on an external web server for the majority of the process. ${ }^{8} \mathrm{I}$ eventually captured 14,658,058 posts either originating from or mentioning Ohio over the course of eleven months. This data collection began in August of 2015 (on the day of the first Republican debate) and ended in July of 2016, when Bernie Sanders endorsed Hillary Clinton for the Democratic nomination. ${ }^{9}$ For each month of collected data, I ran several computational analyses on the tweets, including the use of regular expressions to find common patterns in the data, partof-speech analysis to find and reconstruct common grammatical phrasings, and sentiment analysis to evaluate common emotions found within user posts. ${ }^{10}$ In particular, pattern matching and partof-speech analysis enabled me to extract the most frequently used phrases connected to each individual candidate each month, which led directly to the final form of the installation. The content of these phrase fragments fell on a spectrum from short, generic fragments ("Clinton is trash," "Kasich is a jerk") all the way to recognizable memes, news items, and popular culture ("Ted Cruz is the Zodiac Killer,"11 "Cruz is Lucifer in the flesh,"12 "Trump is John Miller"13). The chronological nature of the data analysis also enabled me to see longitudinal trends in how certain phrases were appearing, such as the persistence of a Twitter meme claiming that "Trump is Sacha Baron Cohen in disguise," or "Ted Cruz is the Zodiac Killer" spiking in popularity in February 2016, when the meme gained traction on other platforms and outlets. ${ }^{14}$

I then used these phrases to alter and redesign my own versions of the campaign merchandise of each candidate. Paying close attention to the design language of each campaign, I meticulously (and by hand) re-created buttons, bumper stickers, rally signs, t-shirts and yard signs to reflect phrases that appeared in the data, creating a hierarchy of merchandise that corresponded to the frequency with which each phrase was found (see figures 1-3). The hierarchy reflected the ease with which I could manufacture each piece of merchandise, along with price; for example, buttons, which were cheap and easy to produce, displayed the lowest ranking phrases, while T-shirts contained the most often-repeated tweets. ${ }^{15}$ The merchandise was displayed chronologically on the walls of the gallery space, beginning with a section devoted to the early campaigns (AugustDecember, 2015) and further segmenting the data into month-by-month sections as the primaries ramped up in intensity (and as the amount of data collected per month correspondingly increased). 


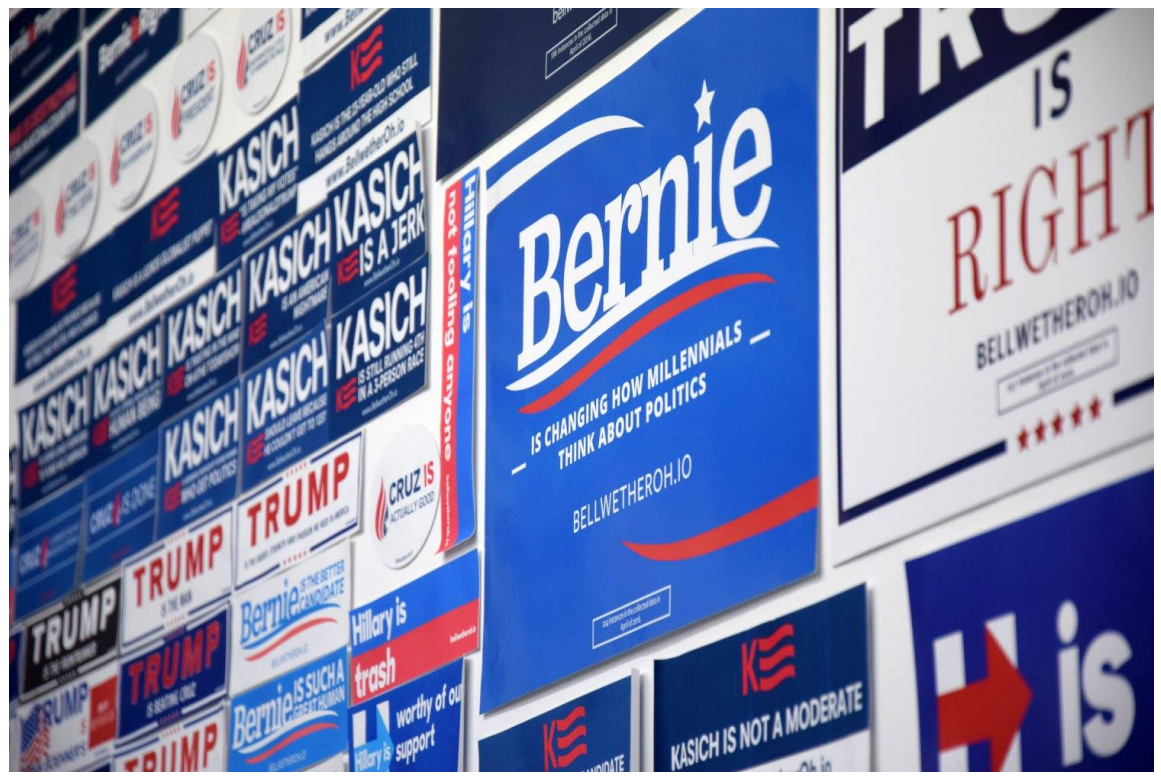

Figure 1. Partial Installation View of \#Bellwether, Harlan Levey Projects, Brussels (November 2016).

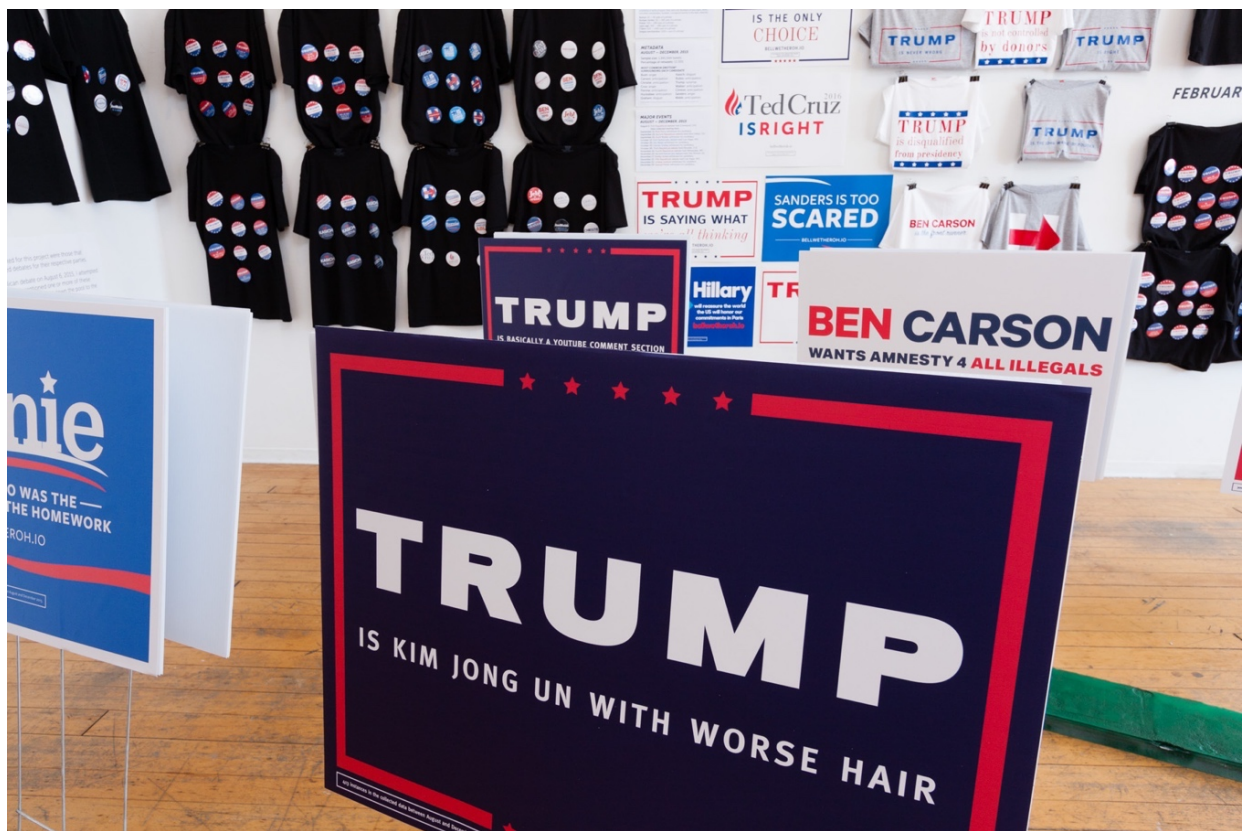

Figure 2. Partial Installation View of \#Bellwether, SPACES, Cleveland, OH (July 2016). 


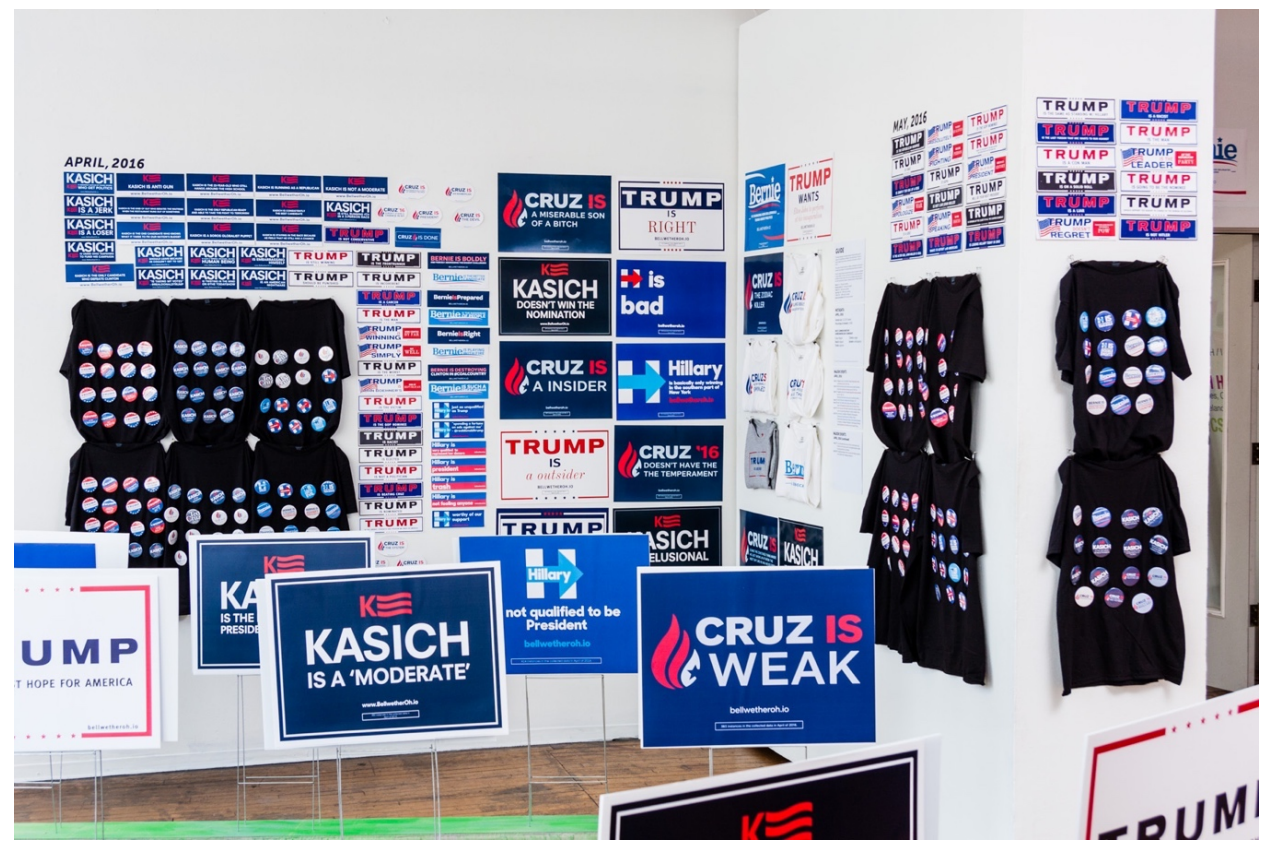

Figure 3. Partial Installation View of \#Bellwether, SPACES, Cleveland, OH (July 2016).

Campaign merchandise has, over the course of American political history, become inextricably tied up with the political identities of candidates and their platforms. ${ }^{16}$ A political paraphernalia collection available to view at the Cleveland City Club contains buttons, ribbons, pamphlets and more from campaigns stretching all the way back to Andrew Jackson's bid for the presidency in 1828. ${ }^{17}$ Design and branding have become imperative to the success of the modern political campaign; in 2008, Barack Obama won universal acclaim for his clean, uniform brand identity, ${ }^{18}$ and in 2015, the logo for Hillary Clinton's second presidential bid found itself placed under a microscope and evaluated for its intent, meaning and overall effectiveness. ${ }^{19}$ Over the course of a single campaign, we come to identify so strongly with the visual language adopted by each candidate that we often do not need to read additional text on their collateral in order to get a sense of the messages they are attempting to convey; as I put it during an October 2016 interview on Live Wire Radio, "How many times have we seen the Hillary Clinton 'Stronger Together' message? How many times have we seen 'Make America Great Again'?,"20

In crafting the merchandise for \#Bellwether, I painstakingly replicated typography choices, colors and logos in order to make my fictional merchandise resemble the real thing as much as possible. This included any changes made to design over time; in particular, both Ted Cruz and Hillary Clinton overhauled their campaigns' look and feel in significant ways over the course of the primary season, which was then reflected in the merchandise on display in my installation as well (fig. 4). By mirroring the official collateral as much as possible, the dissonance between what we are used to seeing reflected in those visuals - the carefully crafted messaging of each candidateand what we actually see in its place becomes stronger and more reflective of the chaotic, fragmented view of the opinion present on social media and in the American electoral process in general. The language on the altered merchandise, which often contains negative sentiments about the candidate that it describes, also serves as a check on the control that the candidates exert over 
their own images. It reminds us that even though they may seem like all-powerful, massive machines, they too are crafting their own images to align with what the country seems to desire, in much the same way that social media offer users "...the perception of control over how their personal narrative connects to the larger whole." 21



\section{Figure 4. An example of the changes made to \#Bellwether as Hillary Clinton changed her graphic identity during her primary campaign.}

\section{EDITOR'S NOTES}

During Trump's 2016 campaign, it became clear that his use of Twitter had been integral to his ability not only to maintain a direct connection to his core voter base, but also to relentlessly capture the attention of the 24-hour news cycle. Twitter served as a form of free advertising for his campaign; the more he posted things that would attract strong reactions from both ends of the political spectrum, the more his name stayed in the news and attention remained on his campaign and actions. ${ }^{22}$ Trump even went so far as to credit social media for his surprise victory in an interview with Lesley Stahl on 60 Minutes: "I think that social media has more power than the money they spent, and I think maybe to a certain extent, I proved that." ${ }^{, 23}$ After his eventual Electoral College win in December, analysts wondered if he would continue to use Twitter in the same way throughout the duration of his presidency. ${ }^{24}$ Trump's tweets have, in fact, continued to serve as a source of media focus for his administration; his Twitter habits appear frequently as breaking news and, often, shift and influence the discussion surrounding his policies and stances. ${ }^{25}$

In the days after Trump's victory, I began assembling an archive of the @realDonaldTrump Twitter account, ${ }^{26}$ primarily relying on the open-source "Get Old Tweets" module for the Python programming language. ${ }^{27}$ With the assistance of this module, I performed month-by-month searches for anything that had been tweeted from this account, beginning with the first posts from 2009, and saved the results in comma-separated value (CSV) files. Using all of the tweets in this archive that were posted ${ }^{28}$ during and after June 2015- when Trump announced his campaign for the presidency - I began juxtaposing the most inflammatory content and actions, which often drew criticism in mainstream news media for contradicting legal or governmental tradition, ${ }^{29}$ alongside the text of the documents to which they were being compared. I later expanded the Trump data corpus to include official announcements or statements that came from his administration, including text of executive orders and proclamations, interviews and press statements, and mass 
emails to his supporters. Over time, the project evolved into a durational, cumulative effort, titled Editor's Notes, in which I edited and changed the text of the Constitution over time to reflect the policy positions and overtly partisan stances that have been evident in the way Trump chooses to present himself to the American public.

Using Trump's own words and actions as a guide, I have made profuse changes to the original text, such as striking out phrases, changing language to reflect a more contemporary application of what are widely considered to be unjust and outdated laws (for example, replacing language in Article IV's Fugitive Slave Clause with that reflecting the more current concept of "sanctuary cities" for undocumented immigrants ${ }^{30}$ ) and warping the concept of government by the people to reflect Trump's clearly stated ideal of government by his rules alone. Each of these changes is footnoted; the footnotes, or "editor's notes" from which the project draws its title, consist of the verbatim statements from Trump and his administration that I am using in order to justify the edits I have made (figure 5). Because I worked with a text corpus consisting of thousands of tweets, as well as hundreds of pages of other source material, I ended up building a simple Python script ${ }^{31}$ for assistance in finding relevant material. The program enabled me to enter key words related to the section of the document I was editing, found matches for those terms in my data corpus, and collected the results in a shorter, more manageable filtered list. It returned that list of potential tweets and phrases as the output, from which I manually selected items to include in the final documents.

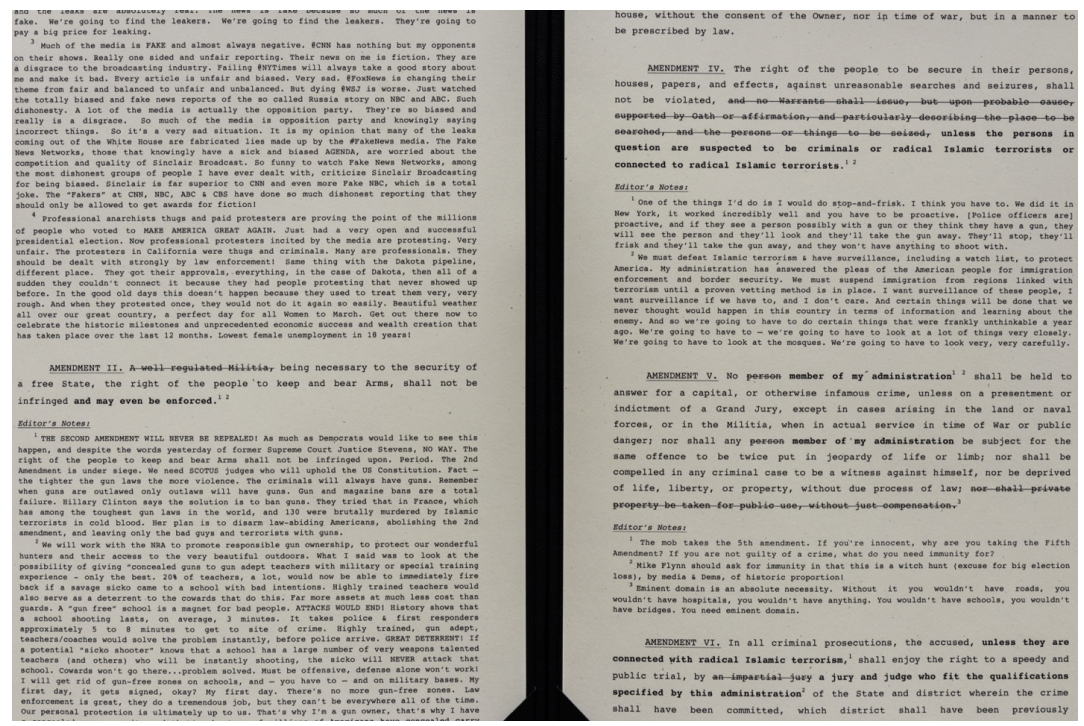

Figure 5. Detail View of Editor's Notes, SPACES, Cleveland, OH (April 2018).

Editor's Notes takes its final form as a fictional Presidential Executive Order, titled "Updating and Fixing Archaic United States Laws" (see figures 6-7). Using publicly available documentation of signings, as well as imagery of past Orders and similar government documents, I have attempted to recreate the look and feel of the ceremonial versions of these documents: I use typefaces that mimic the ones found in photographs of the orders and digital copies available online, laser print the text of the project on heavyweight legal paper, and display them in faux leather document holders that resemble the ones that Trump uses to present them to the press. I also include an 
oversized graphic of Trump's signature on the final page (see figure 8), referencing the observation that his signatures on these documents are bold, prominently placed and often unnaturally large. ${ }^{32}$

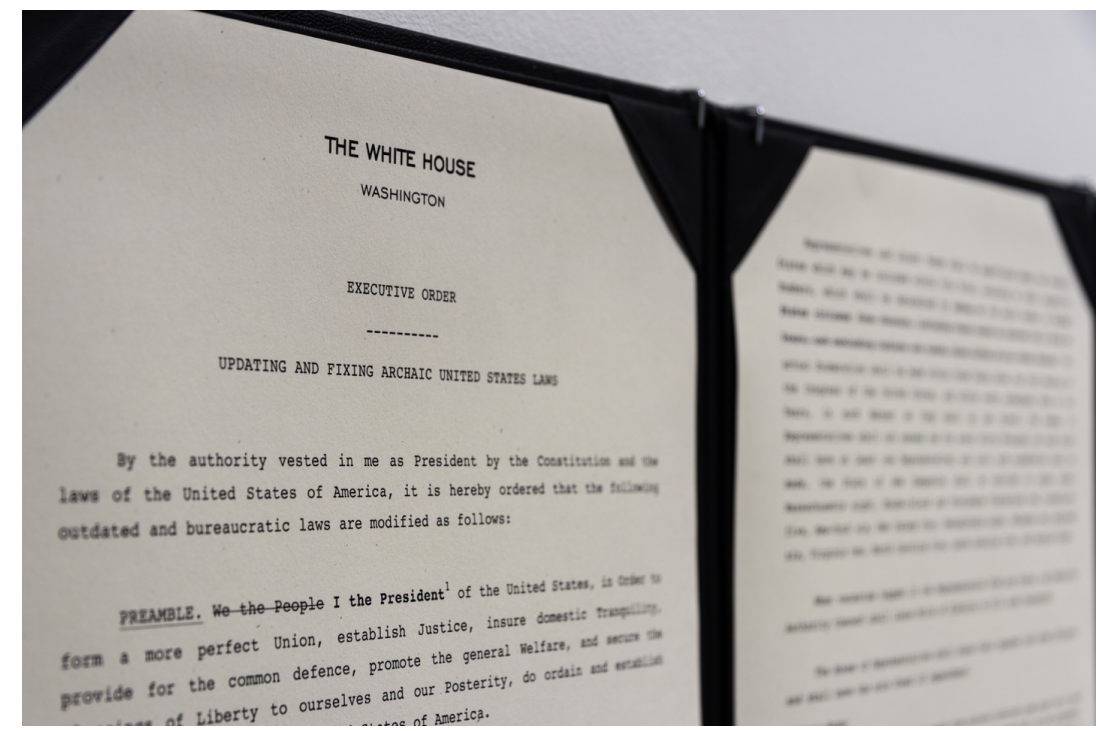

Figure 6. Detail View of Editor's Notes, Including Title, SPACES, Cleveland, OH (April 2018).

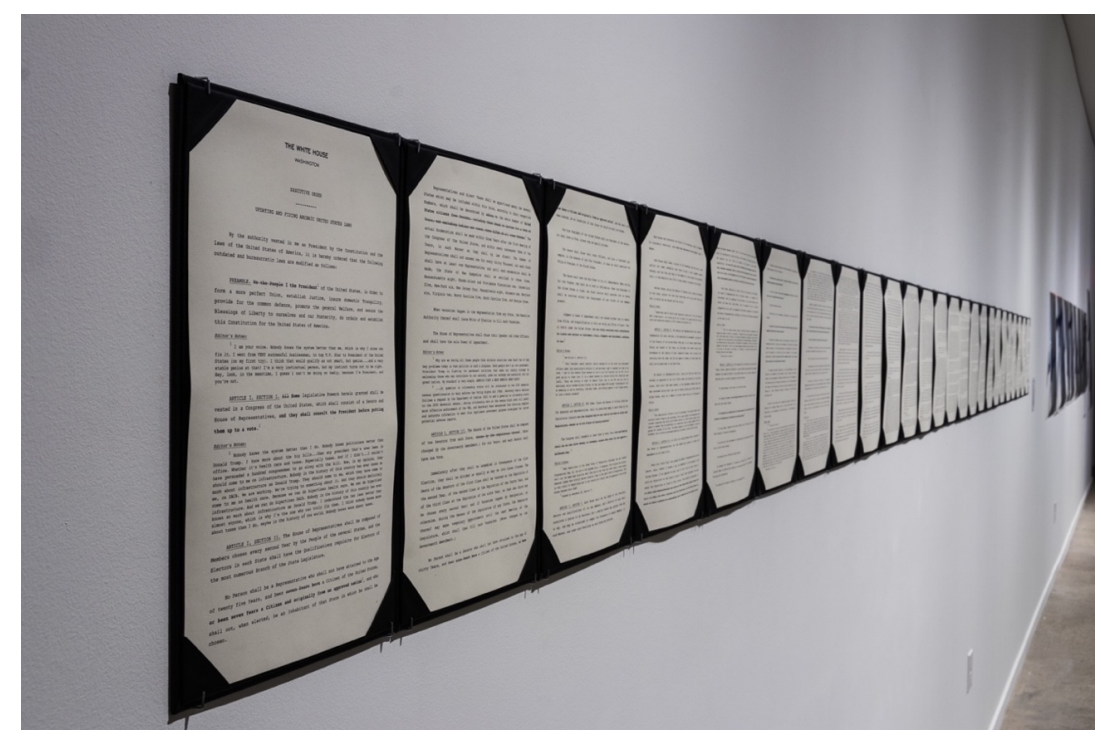

Figure 7. Installation view of Editor's Notes, SPACES, Cleveland, OH (April 2018). 




\section{Figure 8: Detail of Editor's Notes, Including Signature, SPACES, Cleveland, OH (April 2018).}

By attempting to make these documents feel as "official" as possible, I seek to underscore the extreme nature of the language and edits contained within; the incongruity between the edits and the formal manner in which they are presented parallels the disparity between the often facetious and transient way we perceive Trump's tweets in an everyday context and the deeper implications of many of his proclamations and statements. At the same time, seeing Trump's "notes" in this way also highlights the ways in which our current conception of American government necessitates the denial of rights to so many. If, as it has been over time, the Constitution can be "fixed" through the addition of amendments that change fundamental definitions of who qualifies as part of the "people" it describes, it stands to reason that if its power is placed in the wrong hands, those same rights that have been grudgingly given to marginalized populations throughout American history could just as easily be taken away. This points to the long-standing idea that core conceptions of American freedom and equality exclude these marginalized people on a deep, foundational level, and it suggests that it will take much more than language added to a document to truly amend how the United States operates.

\section{THE POLITICAL DOCUMENT, REMIXED AND RECONSIDERED}

There are several forms of remix occurring within both of these projects, some of which involve computational processes and some of which do not. At their core, both of these works rest on a foundation of durational data collection, mainly from online sources, and on using this data in ways that deviate from how it is traditionally represented and accepted. In particular, taking tweets and placing them out of context - in real, physical space, taking up room with their assertions and necessitating a physical, embodied experience, rather than viewing them in a homogenous and never-ending timeline - allows us to consider how the nature of social media prompts us to experience these texts in a way that might otherwise be different. Both projects draw from a tradition of data physicalization, in which data traditionally viewed in a two-dimensional format 
on a screen or as part of a printed text is brought into three- and four-dimensional space. ${ }^{33}$ In their extensive review of projects employing data physicalization, Pierre Dragucevic, Yvonne Jansen and Andrew Vande Moere outline a potential for three- and four-dimensional works to “... 'embod[y]' data rather than...just communicat[e] data by its physical dimensions"; ${ }^{34}$ this allows viewers to engage with these projects through sensory means that are not commonly associated with two-dimensional visualization, such as touch and physical motion. ${ }^{35}$ These tactile and corporeal experiences may thus hew more closely to the human experiences on which they are meant to reflect, as opposed to visualizations that rely on a great deal of graphical flattening and abstraction. ${ }^{36}$

Both \#Bellwether and Editor's Notes utilize remix to speak to this "embodiment" of data by asking us to consider the real-world impact of online behavior on political opinion in ways that do not readily come across on a screen. In removing the data from its original, online context and reframing it in the context of material objects, I attempt to evoke a real-world affective experience independent of the assumptions that come with a specific technological platform or device. For example, navigating a gallery space that has been packed with campaign merchandise, all of it presenting different politically-charged messages (and, more often than not, presenting conflicting messages regarding the same candidate), is a fundamentally different experience from viewing those same tweets in their clean, single-file, endlessly scrolling native interface. This process also strives to put the text in closer conversation with the interpersonal and political conversations on which it is commenting. Being confronted with the cacophony of opposing messages encountered at the same time also asks the viewer to consider the political implication of the echo chambers in which they exist within their own social media environments. Dan Moulthrop, the CEO of the Cleveland City Club, remarked that \#Bellwether allowed the viewer to "... be confronted with everything that people believe that is not what you believe. It's really actually hard, in some ways, to find your own sentiments here, because everybody else's sentiment is also magnified." 37 Here, Moulthrop echoes a sentiment expressed by many visitors to the installation; a common observation was that it was impossible to quickly find something written on any of the merchandise that coincided with one's own views. The real-world experience of sifting through an avalanche of messages to find the ones with which you actually agree differs dramatically from the everyday curation that occurs on a platform like Twitter, where we choose who we follow based on our desire to hear what they have to say. In a review of \#Bellwether for Hyperallergic, critic Julia Christensen noted that “... if you were to run this experiment on just an individual's feed, you'd be looking at a very different set of bumper stickers overall". ${ }^{38}$

The manipulation of commonly accepted visual language in these projects draws from a rich tradition of appropriation art and activism known as culture jamming, in which brands or other ubiquitous visual representations are altered in specific ways in order to convey dissonant or oppositional meanings, engaging in a form of "rhetorical sabotage"; 39 they "...invest ads, newscasts, and other media artifacts with subversive meanings; simultaneously, they decrypt them, rendering their seductions impotent." 40 Culture jamming functions by tapping into what Bernard Stiegler has theorized as the hypomnesis that accompanies the ascendance of cultural capitalism, the externalization of memory into material forms. ${ }^{41}$ For Stiegler, the shift of personal memory into these external modes, or what he calls mnemotechnologies, allows for a redistribution of power benefiting those who control and manage the objects to which we entrust our knowledge. 42 The act of culture jamming disrupts this process by interfering in its naturalization (what Stiegler refers to as "grammatisation"), underscoring the constructed nature of the relationship between 
the object and the meaning with which we associate it, and offering an oppositional, subversive or incongruous alternative. ${ }^{43}$

Culture jamming is commonly associated with the hijacking of capitalist tropes and conventions, evident in the work of groups like AdBusters that attack consumer culture through their appropriation of well-known advertisements and logos; ${ }^{44}$ exchanges like Jonah Peretti's now infamous Nike sweatshop emails; ${ }^{45}$ or in politically dissident projects such as Cliff Roth's video remix of Ronald and Nancy Reagan appearing to advocate for drug use in the midst of the War on Drugs and "Just Say No" campaign. ${ }^{46}$ However, its practices are also effectively utilized in more nuanced projects such as the Yes Men's New York Times Special Edition, in which the standard format of both the print and online versions of the New York Times was filled with fictional, utopian articles and used to project the collective optimism and hope present in the liberal wing of the US after the election of Barack Obama to the presidency in 2008. ${ }^{47}$ The use of the Times' familiar layout prompted a "double take" response; those who encountered the fictional newspaper were left wondering whether or not the events taking place in its pages were "real," and were, by extension, prompted to imagine what the world would be like if they were. ${ }^{48}$

In the same vein as the Yes Men's project, \#Bellwether and Editor's Notes use design language that is strongly associated with the American political tradition in order to express sentiments or intentions that differ wildly from what we have come to expect from these media or forms. In these instances, remix is used not only to place the data in unfamiliar spatial and temporal contexts, but also to illuminate and challenge what we take for granted in political discourse by creating dissonance between the visuals we expect and those that we encounter. Encountering a visually accurate Hillary Clinton sign stating that she "is just as unqualified as Trump" or a Bernie Sanders button that claims he "is just a nice old man who wanted to help us" deviates from the messaging we have come to expect when we encounter objects such as these in the real world, where they typically project banalities relating to patriotism and change. The replacement of these platitudes with the colorful, emphatic and often vitriolic language that we have become used to seeing on social media calls into question the candidates' bland, highly vetted messaging and makes us wonder whether or not we are seeing them for who they truly are. At the same time, it brings to light the one-sidedness that we have come to expect from the American political machine. Similarly, seeing Trump's crude and inflammatory Twitter language juxtaposed with the Constitution, in a context in which we often expect to see obtuse, indecipherable legal jargon, calls attention to the fact that his presidency does not align with the type of behavior we have come to expect from the office, ${ }^{49}$ and that because of this, we might overlook actions and words that could have alarming consequences for the country if left unchecked.

The use of culture jamming in Editor's Notes also contributes to its cautionary nature; in many key ways, the project draws from a tradition of speculative art making, in which divergent expressions of dominant narratives are employed in order to hint at the potential for alternate futures, or, in this case, an eventual outcome of a current trajectory. ${ }^{50}$ In particular, Anthony Dunne and Fiona Raby point to the role of speculative "dark" design in "...draw[ing] attention to a scary possibility in the form of a cautionary tale." 51 They emphasize the necessity of approaching this type of critique through worldbuilding in a nuanced, multifaceted way, rather than simply relying on shock value. ${ }^{52}$ Dunne and Raby point to the Yes Men's New York Times project as doing exactly this; in the artists' words, the project works by “...describing what the future could hold, if we 
forced Obama to be the president we'd elected him to be,"53 and Dunne and Raby highlight the detail and subtlety of its design as particularly effective. ${ }^{54}$ In Editor's Notes, the imagining of a world in which Trump can and does edit the Constitution through a series of Executive Orders underscores the liberties that he has taken with the Orders that he has issued as part of his presidency, such as implementing a travel ban on specific nations, attempting to weaken the Affordable Care Act, and rolling back environmental protections. ${ }^{55}$ The exaggerated extension of this behavior to encompass the highest guiding document in the nation, employing detailed visual cues associated with governmental and legal standards, offers an approach to the analysis of Trump's behavior that goes further than the immediate ramifications of his actions, on which the media so often fixate. It instead asks us to consider what the long-term implications of this behavior are, and what he might be suggesting about his view of his own power. By examining the accumulation of Trump's collected output, rather than individual utterances or tweets as they arise, the project takes the current state of the presidency to a logical future conclusion and suggests that, left unchecked, Trump's ability to manipulate and ignore government standards may bring about a very similar outcome to the one envisioned in the fictional Executive Order.

\section{CONCLUSION}

Through a study of two art projects in which I manipulate well-known political design language in order to question the foundations on which these traditions are built, I have attempted to demonstrate that utilizing remix and appropriation in this context can call into question the assumptions that we make surrounding American political traditions and the people who uphold them.

The aim of these works is to encourage audiences to question who is responsible for the political messaging that we consume on a regular basis; what the motivations behind it may be; the effects of the platforms and media by which we come across this information; and the possible consequences resulting from our passive consumption. In \#Bellwether, the construction of a visually and spatially overwhelming "field" of merchandise out of tweets, in which it is impossible to silo or filter out views with which you do not agree, offers an opportunity to rethink the relationship between the content of the text and how its presence in an online environment affects how we interpret and contextualize it. Placing the Twitter data in a real-world, offscreen context prevents us from defaulting to the strategies we would normally use in order to consume it; formatting it to replace traditional slogans on official merchandise invites the viewer to question the ways in which design is used to legitimate political campaign message dissemination. Likewise, Editor's Notes uses appropriation of formal legal design and presentation in order to lend a semblance of permanence to otherwise ephemeral data-and allows us to consider more closely the serious, durational implications of Trump's statements, which are often treated as fleeting or volatile. Both projects employ remix by recontextualizing content that we have come to take for granted as both existing in its original state and imparting specific meaning, in order to invite challenge, pushback and deeper examination.

By utilizing objects that closely resemble that which they are mimicking, but making them deviate from the originals in key ways, these works give the viewer what Paolo Peverini calls "...the ability to 'read' [their] different levels...which then subsequently creates a controlled transformation." 56 For Peverini, the effectiveness of the appropriative or "rewriting" strategy, as he calls it, lies in the resultant work's ability to refer meaningfully back its source; ${ }^{.5}$ \#Bellwether 
and Editor's Notes utilize specific, commonly accepted conceptions of both the textual style associated with Twitter and the design language of politics to suggest opportunities to critique what we perceive as the status quo in both areas. The multifaceted texts and proliferation of data contained within these pieces also offer a chance for audiences to consider key questions of context, authorship and control in the creation of visual signifiers that we may have come to take for granted. These techniques undermine the authority of those responsible for the creation of these signifiers, and they have the potential to lead to the imagining of radically different political outcomes.

\section{ACKNOWLEDGEMENTS}

I thank Christina Vassallo, Bruce Edwards, Karl Anderson, Harlan Levey, Will Owen, Rachel Vera Steinberg and Janna Dyk for their curatorial support of the projects discussed in this article. I am also grateful to the editors of this issue and the anonymous reviewer for their valuable feedback during the publication process.

\section{ENDNOTES}

1. \#Bellwether was originally commissioned by SPACES in Cleveland, Ohio, as part of the SPACES World Artists Program, during the May-July 2016 season. I focused on the Ohio voter for this project because the gallery wanted it to reflect the geographical specificity of its audience, and because its initial exhibition coincided with the Republican National Convention's presence in the city. I am also originally from the Cleveland area, which added additional personal resonance to the work.

2. Paolo Peverini, "Remix Practices and Activism: A Semiotic Analysis of Creative Dissent," in The Routledge Companion to Remix Studies, eds., Eduardo Navas, Owen Gallagher and xtine burrough (New York: Routledge 2015), 333.

3. The title \#Bellwether is both a reference to Ohio's commonly referenced status as a "bellwether state," as well as to the social media data from which the installation draws.

4. Mat Honan, "Twitter's New Political Index Proves Big Data Knows What You're Thinking," Wired, August 1, 2012, https://wired.com/2012/08/twindex_twitter_politicalindex; Sarah Perez, “The AP Debuts 'Election Buzz,' a Tool That Uses Twitter and Google Data to Track the US Elections," TechCrunch, March 1, 2016, https://techcrunch.com/2016/03/01/the-ap-debutselection-buzz-a-tool-that-uses-twitter-and-google-data-to-track-the-u-s-elections/.

5. Roopa Vasudevan, "Memes, Merch and the Media in the 2016 Election," Adjacent: The ITP/IMA Journal of Emerging Media, 3 (2018), https://itp.nyu.edu/adjacent/issue-3/memesmerch-and-the-media-in-the-2016-election-2/.

6. Twitter's standard API allows access to only $1 \%$ of public tweets at any given point in time, which is why it is crucial to note that this project used only the data that I was able to gather, and not every available tweet (as some have believed).

7. See https://pypi.org/project/twitter/.

8. Codebase for this project available at https://github.com/rouxpz/bellwether.

9. Vasudevan.

10. Ibid. A more detailed description of the computational analysis used in \#Bellwether can be found in this article. 
11. Michelle Dean, "Ted Cruz Is the Zodiac Killer: The Anatomy of a Meme Gone Rogue," The Guardian, March 9, 2016, https://theguardian.com/us-news/2016/mar/09/ted-cruz-zodiac-killermeme.

12. Nick Gass, "Boehner: Cruz Is 'Lucifer in the Flesh,"” POLITICO, April 28, 2016, https://www.politico.com/story/2016/04/john-beohner-ted-cruz-lucifer-222570.

13. Marc Fisher and Will Hobson, "Donald Trump Masqueraded As Publicist to Brag about Himself," The Washington Post, May 13, 2016,

https:/www.washingtonpost.com/politics/donald-trump-alter-ego-barron/2016/05/12/02ac99ec16fe-11e6-aa55-670cabef46e0 story.html.

14. Dean; Vasudevan.

15. Vasudevan.

16. Judith S. Trent, Robert V. Friedenberg, and Robert E. Denton, Political Campaign

Communication: Principles and Practices (Lanham, MD: Rowman \& Littlefield Publishers, 2011), 272.

17. Josh Vodrey, "From Jackson to Obama: Political Treasures on Display," The City Club of Cleveland, August 15, 2014, https:/www.cityclub.org/blog/2014/08/15/from-jackson-to-obamapolitical-treasures-on-display; Vasudevan. This collection was an enormous inspiration for the eventual output of the installation.

18. See also the 2018 congressional campaign of Alexandria Ocasio-Cortez, the design of which was praised as bold, unique and expertly tailored to her constituency (Diana Budds, "The Brilliance of Alexandria Ocasio-Cortez's Bold Campaign Design,” Vox, July 2, 2018, https:/www.vox.com/policy-and-politics/2018/7/2/17519414/ocasio-cortez-campaign-designcampaign-posters-tandem-branding); and the branding for the slate of candidates for the 2020 Democratic presidential primary (Eliza Brooke, "What the 2020 Presidential Candidates' Logos Tell Us, Explained by Design Experts," Vox, May 15, 2019, https://www.vox.com/thegoods/2019/3/29/18284489/2020-presidental-candidate-logos-democrats). In 2019, I created an online extension of \#Bellwether, entitled \#CrowdedField

(http://www.dilettantearmy.com/articles/crowdedfield), which consisted of animated GIFs juxtaposing the 2020 candidates' graphic design with collected tweets discussing their candidacies.

19. Andrew Romano, "Expertinent: Why the Obama 'Brand' Is Working," Newsweek, 27

February 2008, https://newsweek.com/expertinent-why-obama-brand-working-219922; Michael Beirut, "I'm with Her," Design Observer, 28 March 2017, https://designobserver.com/feature/im-with-her/39523; Vasudevan.

20. Roopa Vasudevan, interview by Luke Burbank, Live Wire Radio, Oregon Public Broadcasting, October 21, 2016.

21. Julia Christensen, "During the RNC, Two Art Projects Amplify the Voices of Ohio's Citizens," Hyperallergic, July 19, 2016, https://hyperallergic.com/312177/during-the-rnc-twoart-projects-amplify-the-voices-of-ohios-citizens/.

22. Michael Barbaro, "Pithy, Mean and Powerful: How Donald Trump Mastered Twitter for 2016," New York Times, October 5, 2015. nytimes.com/2015/10/06/us/politics/donald-trumptwitter-use-campaign-2016.html.

23. Donald Trump, interview by Lesley Stahl, 60 Minutes, CBS, 13 November 2016.

24. Tamara Keith, “Commander-In-Tweet: Trump's Social Media Use And Presidential Media Avoidance," NPR, November 18, 2016,

https://www.npr.org/2016/11/18/502306687/commander-in-tweet-trumps-social-media-use-andpresidential-media-avoidance. 
25. Michael D. Shear et al., "How Trump Reshaped the Presidency in Over 11,000 Tweets," New York Times, November 2, 2019,

https://www.nytimes.com/interactive/2019/11/02/us/politics/trump-twitter-presidency.html. 26. Other projects have also been engaged in the same effort, most notably the Trump Twitter Archive (http://www.trumptwitterarchive.com) and Factbase (https://factba.se/topic/twitter). 27. See https://github.com/Jefferson-Henrique/GetOldTweets-python.

28. There have been widely reported instances in which Trump or his social media staff posted something to his account, only to remove it due to backlash from the mainstream media or typographical errors (see Rachel Treisman, "As President Trump Tweets and Deletes, the Historical Record Takes Shape,” NPR, October 25, 2019, https://www.npr.org/2019/10/25/772325133/as-president-trump-tweets-and-deletes-thehistorical-record-takes-shape). In my personal data collection efforts, some of these deleted tweets may have been missed as a result.

29. Shear et al.; Corey Brettschneider, "Trump vs. the Constitution: A Guide," POLITICO, August 4, 2016, https://www.politico.com/magazine/story/2016/08/2016-donald-trumpconstitution-guide-unconstitutional-freedom-liberty-khan-214139; Adam Liptak, "New on This Fall's Law School Syllabus: Trump", New York Times, August 14, 2017, https://www.nytimes.com/2017/08/14/us/politics/trump-constitution-law-schools.html. 30. James A. Kraehenbuehl, "Lessons from the Past: How the Antebellum Fugitive Slave Debate Informs State Enforcement of Federal Immigration Law," The University of Chicago Law Review, 78 no. 4 (2011): 1472; Sean Trainor, "What the Fugitive Slave Act Can Teach Us About Sanctuary Cities," Time, February 7, 2017, https://time.com/4659391/sanctuary-citiesfugitive-slave-act/.

31. Codebase available at https://github.com/rouxpz/editors-notes.

32. Sam Wolfson, "Notes on a scandal: Why Trump Loves to Scrawl in Marker Pen," The Guardian, July 18, 2018, https://www.theguardian.com/us-news/2018/jul/18/donald-trumpmarker-pen-sharpie-russia-putin-scandal; Sam Haysom, "J.K. Rowling Takes Aim at Donald Trump's Massive Signature on Twitter," Mashable, May 10, 2018, https://mashable.com/2018/05/10/j-k-rowling-donald-trump-signature/.

33. Trevor Hogan et al., "Tangible Data, Explorations in Data Physicalization," Proceedings of the TEI '16: Tenth International Conference on Tangible, Embedded, and Embodied Interaction - TEI '16, 2016, https://doi.org/10.1145/2839462.2854112.

34. Pierre Dragucevic, Yvonne Jansen, and Andrew Vande Moere, "Data Physicalization," in Springer Handbook of Human Computer Interaction, ed. Jean Vanderdonckt (Springer 2020), $34-35$.

35. Ibid, 35 .

36. Ibid, 37.

37. spacesgallery, "SWAP \#55: Roopa Vasudevan," YouTube video, 4:44, August 30, 2016 https://www.youtube.com/watch?v=72hYncAMe6o.

38. Christensen.

39. Christine Harold, "Pranking Rhetoric: 'Culture Jamming' as Media Activism," in Culture Jamming: Activism and the Art of Cultural Resistance, eds., Marilyn DeLaure and Moritz Fink (New York: NYU Press 2017), 63.

40. Mark Dery, "Culture Jamming: Hacking, Slashing and Sniping in the Empire of Signs," in Culture Jamming: Activism and the Art of Cultural Resistance, eds., Marilyn DeLaure and Moritz Fink (New York: NYU Press 2017), 47. 
41. Bernard Stiegler, "Anamnesis and Hypomnesis: Plato as the first thinker of the proletarianisation," Ars Industrialis, 2007, http://arsindustrialis.org/anamnesis-and-hypomnesis. 42. Ibid.

43. Ibid; Dery, 46-47.

44. Jeff Sommer, "The War Against Too Much of Everything”, New York Times, December 22, 2012, https://www.nytimes.com/2012/12/23/business/adbusters-war-against-too-much-ofeverything.html; Dery, 49-50; Harold, 62-63.

45. Jonah Peretti, "Culture Jamming, Memes, Social Networks, and the Emerging Media Ecology: The 'Nike Sweatshop Email' as Object-To-Think-With,"

https://depts.washington.edu/ccce/polcommcampaigns/peretti.html, accessed June 16, 2020. 46. Jonathan McIntosh, "A History of Subversive Video Remix before YouTube: Thirty Political Video Mashups Made between World War II and 2005," Transformative Works and Cultures, no. 9 (2012), http://dx.doi.org/10.3983/twc.2012.0371; Jesse Drew, "Radical Remix: Manifestoon," in The Routledge Companion to Remix Studies, eds., Eduardo Navas, Owen Gallagher and xtine burrough (New York: Routledge 2015), 506.

47. The Yes Men, "Hijinks/New York Times Special Edition," https://theyesmen.org/project/nytimes, accessed June 19, 2020; Sewell Chan, "Liberal Pranksters Hand Out Times Spoof," City Room, New York Times, November 12, 2008, https:/cityroom.blogs.nytimes.com/2008/11/12/pranksters-spoof-the-times.

48. Ibid.

49. James Fallows, “The Daily Trump: Filling a Time Capsule", Reporter's Notebook, The Atlantic, October 20, 2016, https://www.theatlantic.com/notes/all/2016/05/the-dailytrump/484064/; Peter Baker, “On Day 1,001, Trump Made It Clear: Being 'Presidential' Is Boring," New York Times, October 18, 2019, https:/www.nytimes.com/2019/10/18/us/politics/trump-presidency.html.

50. Anthony Dunne and Fiona Raby, Speculative Everything: Design, Fiction, and Social Dreaming (Cambridge, MA: MIT Press 2013), 2-3; Vanina Hoffman and Pau Alsina, "Art and Speculative Futures 'What Would Happen If...?"' Artnodes, 2017, no. 19 (2017), 2. This form is closely related to the Afrofuturist artistic tradition (see Alondra Nelson, "Introduction: Future Texts," Social Text, 20 no. 2 [2002].)

51. Dunne and Raby, 38.

52. Ibid, 40.

53. The Yes Men.

54. Dunne and Raby, 40.

55. Aidan Quigley, “All of Trump's Major Executive Actions So Far,” POLITICO, January 25, 2017, https:/www.politico.com/agenda/story/2017/01/all-trump-executive-actions-000288. 56. Peverini, 339.

57. Ibid.

\section{REFERENCES}

Baker, Peter. “On Day 1,001, Trump Made It Clear: Being 'Presidential' Is Boring.” New York Times, October 18, 2019. https://www.nytimes.com/2019/10/18/us/politics/trumppresidency.html. 
Barbaro, Michael. "Pithy, Mean and Powerful: How Donald Trump Mastered Twitter for 2016." New York Times, October 5, 2015. nytimes.com/2015/10/06/us/politics/donald-trumptwitter-use-campaign-2016.html.

Beirut, Michael. “I'm With Her.” Design Observer, March 28, 2017. designobserver.com/feature/im-with-her/39523.

Brettschneider, Corey. “Trump vs. the Constitution: A Guide.” POLITICO, August 4, 2016. https:/www.politico.com/magazine/story/2016/08/2016-donald-trump-constitutionguide-unconstitutional-freedom-liberty-khan-214139.

Brooke, Eliza. "What the 2020 Presidential Candidates' Logos Tell Us, Explained by Design Experts." Vox, May 15, 2019. https://www.vox.com/thegoods/2019/3/29/18284489/2020-presidental-candidate-logos-democrats.

Budds, Diana. "The Brilliance of Alexandria Ocasio-Cortez's Bold Campaign Design.” Vox, July 2, 2018. https://www.vox.com/policy-and-politics/2018/7/2/17519414/ocasiocortez-campaign-design-campaign-posters-tandem-branding.

Chan, Sewell. "Liberal Pranksters Hand Out Times Spoof." City Room, New York Times, November 12, 2008. https://cityroom.blogs.nytimes.com/2008/11/12/pranksters-spoofthe-times.

Christensen, Julia. "During the RNC, Two Art Projects Amplify the Voices of Ohio's Citizens." Hyperallergic, July 19, 2016. https://hyperallergic.com/312177/during-the-rnc-two-artprojects-amplify-the-voices-of-ohios-citizens/.

Dean, Michelle. "Ted Cruz Is the Zodiac Killer: The Anatomy of a Meme Gone Rogue." The Guardian, 9 March 2016. theguardian.com/us-news/2016/mar/09/ted-cruz-zodiac-killermeme. Accessed 5 September 2017.

Dery, Mark. "Culture Jamming: Hacking, Slashing and Sniping in the Empire of Signs." In Culture Jamming: Activism and the Art of Cultural Resistance. Edited by Marilyn DeLaure and Moritz Fink, 39-61. New York: NYU Press, 2017.

Dragucevic, Pierre, Jansen, Yvonne and Vande Moere, Andrew. "Data Physicalization.” In Springer Handbook of Human Computer Interaction. Edited by Jean Vanderdonckt. Springer, 2020.

Drew, Jesse. "Radical Remix: Manifestoon." In The Routledge Companion to Remix Studies. Edited by Eduardo Navas, Owen Gallagher and xtine burrough, 503-508. New York: Routledge, 2015.

Dunne, Anthony and Raby, Fiona. Speculative Everything: Design, Fiction, and Social Dreaming. Cambridge, MA: MIT Press, 2013. 
Fallows, James. “The Daily Trump: Filling a Time Capsule.” Reporter's Notebook, The Atlantic, October 20, 2016. https:/www.theatlantic.com/notes/all/2016/05/the-dailytrump/484064/.

Fisher, Marc, and Will Hobson. "Donald Trump Masqueraded As Publicist to Brag about Himself." The Washington Post, May 13, 2016.

https://www.washingtonpost.com/politics/donald-trump-alter-egobarron/2016/05/12/02ac99ec-16fe-11e6-aa55-670cabef46e0_story.html.

Gass, Nick. "Boehner: Cruz is 'Lucifer in the Flesh."” POLITICO, April 28, 2016. https://www.politico.com/story/2016/04/john-beohner-ted-cruz-lucifer-222570.

Harold, Christine. "Pranking Rhetoric: 'Culture Jamming' as Media Activism." In Culture Jamming: Activism and the Art of Cultural Resistance. Edited by. Marilyn DeLaure and Moritz Fink, 62-90. New York: NYU Press, 2017.

Haysom, Sam. “J.K. Rowling Takes Aim at Donald Trump's Massive Signature on Twitter." Mashable, May 10, 2018. https://mashable.com/2018/05/10/j-k-rowling-donald-trumpsignature/.

Hoffman, Vanina, and Alsina, Pau, "Art and Speculative Futures 'What Would Happen If...?"” Artnodes, 2017 no. 19 (2017): 2-6.

Hogan, Trevor, Eva Hornecker, Simon Stusak, Yvonne Jansen, Jason Alexander, Andrew Vande Moere, Uta Hinrichs, and Kieran Nolan. "Tangible Data, Explorations in Data Physicalization." Proceedings of the TEI '16: Tenth International Conference on Tangible, Embedded, and Embodied Interaction - TEI '16, 2016. https://doi.org/10.1145/2839462.2854112.

Honan, Mat. “Twitter's New Political Index Proves Big Data Knows What You're Thinking." Wired, 1 August 2012. https://wired.com/2012/08/twindex_twitter_politicalindex.

Keith, Tamara. “Commander-In-Tweet: Trump's Social Media Use and Presidential Media Avoidance." NPR, November 18, 2016.

https://www.npr.org/2016/11/18/502306687/commander-in-tweet-trumps-social-mediause-and-presidential-media-avoidance.

Kraehenbuehl, James A. "Lessons from the Past: How the Antebellum Fugitive Slave Debate Informs State Enforcement of Federal Immigration Law," The University of Chicago Law Review, 78 no. 4 (2011): 1465-502.

Liptak, Adam. "New on This Fall's Law School Syllabus: Trump.” New York Times, August 14, 2017. https://www.nytimes.com/2017/08/14/us/politics/trump-constitution-lawschools.html. 
McIntosh, Jonathan. "A History of Subversive Video Remix before YouTube: Thirty Political Video Mashups Made between World War II and 2005." Transformative Works and Cultures, no. 9 (2012), http://dx.doi.org/10.3983/twc.2012.0371.

Nelson, Alondra. “Introduction: Future Texts.” Social Text, 20, no. 2 (2002): 1-15.

Peretti, Jonah. "Culture Jamming, Memes, Social Networks, and the Emerging Media Ecology: The 'Nike Sweatshop Email' as Object-To-Think-With." https://depts.washington.edu/ccce/polcommcampaigns/peretti.html. Accessed June 16, 2020.

Perez, Sarah. “The AP Debuts 'Election Buzz', a Tool That Uses Twitter and Google Data to Track the US Elections." TechCrunch, 1 March 2016.

https://techcrunch.com/2016/03/01/the-ap-debuts-election-buzz-a-tool-that-uses-twitterand-google-data-to-track-the-u-s-elections.

Peverini, Paolo. "Remix Practices and Activism: A Semiotic Analysis of Creative Dissent." In The Routledge Companion to Remix Studies. Edited by Eduardo Navas, Owen Gallagher and xtine burrough, 333-45. New York: Routledge, 2015.

Quigley, Aidan. “All of Trump's Major Executive Actions So Far.” POLITICO, January 25, 2017. https://www.politico.com/agenda/story/2017/01/all-trump-executive-actions000288.

Romano, Andrew. "Expertinent: Why the Obama 'Brand' Is Working." Newsweek, 27 February 2008.

Shear, Michael D., Maggie Haberman, Nicholas Confessore, Karen Yourish, Larry Buchanan, and Keith Collins. "How Trump Reshaped the Presidency in Over 11,000 Tweets." New York Times, November 2, 2019.

https://www.nytimes.com/interactive/2019/11/02/us/politics/trump-twitterpresidency.html.

Sommer, Jeff. "The War Against Too Much of Everything." New York Times, December 22, 2012. https:/www.nytimes.com/2012/12/23/business/adbusters-war-against-too-muchof-everything.html.

spacesgallery. "SWAP \#55: Roopa Vasudevan.” YouTube video, 4:44, August 30, 2016. https:/www.youtube.com/watch?v=72hYncAMe6o.

Stiegler, Bernard. "Anamnesis and Hypomnesis: Plato As the First Thinker of the Proletarianisation," Ars Industrialis, 2007. http://arsindustrialis.org/anamnesis-andhypomnesis.

Trainor, Sean. "What the Fugitive Slave Act Can Teach Us About Sanctuary Cities." Time, February 7, 2017. https://time.com/4659391/sanctuary-cities-fugitive-slave-act/. 
Treisman, Rachel. "As President Trump Tweets and Deletes, The Historical Record Takes Shape.” NPR, October 25, 2019. https://www.npr.org/2019/10/25/772325133/aspresident-trump-tweets-and-deletes-the-historical-record-takes-shape.

Trent, Judith S., Robert V. Friedenberg, and Robert E. Denton. Political Campaign Communication: Principles and Practices. Lanham, MD: Rowman \& Littlefield Publishers, 2011.

Trump, Donald. Interview by Lesley Stahl. 60 Minutes. CBS, November 13, 2016.

Vasudevan, Roopa. Interview by Luke Burbank. Live Wire Radio. Oregon Public Broadcasting, October 21, 2016.

—. "Memes, Merch and the Media in the 2016 Election." Adjacent: The ITP/IMA Journal of Emerging Media, 3 (2018), https://itp.nyu.edu/adjacent/issue-3/memes-merch-andthe-media-in-the-2016-election-2/.

Vodrey, Josh. "From Jackson to Obama: Political Treasures on Display." The City Club of Cleveland, August 15, 2014. https://www.cityclub.org/blog/2014/08/15/from-jacksonto-obama-political-treasures-on-display.

Wolfson, Sam. "Notes on a Scandal: Why Trump Loves to Scrawl in Marker Pen." The Guardian, July 18, 2018. https://www.theguardian.com/us-news/2018/jul/18/donaldtrump-marker-pen-sharpie-russia-putin-scandal.

The Yes Men. "Hijinks/New York Times Special Edition.” Accessed June 19, 2020. https://theyesmen.org/project/nytimes.

\section{AUTHOR BIO}

Roopa Vasudevan is an artist, programmer, and researcher, based in Philadelphia. Her work uses data and technology in order to interrogate or subvert social and cultural practices, focusing on issues of human identity and agency in the digital era; power relationships and how they manifest through technology; and establishing more creative and ethical practices for tech-based art and design. She is a member of Vox Populi, an artist-run gallery space and collective in Philadelphia, and is pursuing her $\mathrm{PhD}$ at the Annenberg School for Communication at the University of Pennsylvania, where she studies the relationships between new media artists and the technology industry. 